\title{
Polarization-preserving holey fibers
}

\section{Broeng, Jes; Mogilevtsev, Dmitri; Libori, Stig E. Barkou; Bjarklev, Anders Overgaard}

\section{Published in:}

Proceedings on The 4th Pacific Rim Conference on Lasers and Electro-Optics

Link to article, DOI:

10.1109/CLEOPR.2001.967699

Publication date:

2001

Document Version

Publisher's PDF, also known as Version of record

Link back to DTU Orbit

Citation (APA):

Broeng, J., Mogilevtsev, D., Libori, S. E. B., \& Bjarklev, A. O. (2001). Polarization-preserving holey fibers. In Proceedings on The 4th Pacific Rim Conference on Lasers and Electro-Optics (Vol. 1) https://doi.org/10.1109/CLEOPR.2001.967699

\section{General rights}

Copyright and moral rights for the publications made accessible in the public portal are retained by the authors and/or other copyright owners and it is a condition of accessing publications that users recognise and abide by the legal requirements associated with these rights.

- Users may download and print one copy of any publication from the public portal for the purpose of private study or research.

- You may not further distribute the material or use it for any profit-making activity or commercial gain

- You may freely distribute the URL identifying the publication in the public portal 


\title{
MA1-3
}

\section{Polarization-preserving holey fibers}

\author{
Jes Broeng, Dmitri Mogilevtsev, Stig E. Barkou Libori, and Anders Bjarklev
}

$$
\begin{gathered}
\text { Center for Communications, Optics and Materials (COM), } \\
\text { Technical University of Denmark, Building 349, DK-2800 Lyngby, Denmark } \\
\text { Tel. +4545253810,E-mail: jb@com.dtu.dk }
\end{gathered}
$$

Abstract.

In this work we suggest and discuss a microstructure of air capillaries with elliptical cross-section in a tread of glass that gives opportunity for creation of polarization-preserving fiber with very small beat length between the fundamental modes of different polarization.

In 1996 a first working example of so called "endlessly single mode photonic crystal fiber" was reported [1]. It should be noted that the fundamental mode for such a fiber consists actually of two degenerate modes. This polarization degeneracy may be removed by breaking the symmetry of the structure, and usually is removed due to imperfections of shapes and positions of holes occurring in the process of manufacturing. For another type of photonic crystal fiber (so-called photonic band-gap crystal fiber, which guides light due to presence of band-gap in the lattice of cladding holes [2]), birefringence induced by imperfections or breaking symmetry defect can be as large as 0.01 [3]. However, in all previous works on photonic crystal fibers it was assumed that the cladding holes ideally are circular-symmetric, and that the fundamental cladding mode is degenerate.

In our work we present a design of index-guiding photonic crystal fiber with elliptically shaped air capillaries. A core region in such fiber is formed by a smaller elliptical hole (Fig.1). As it will be seen later, such design allows to introduce strong birefringence, and to make a photonic crystal polarization-preserving fiber with extremely small beat length.

To model the waveguiding properties of the suggested fibers we use a biorthogonal plane-wave method as it is described in the work [4].

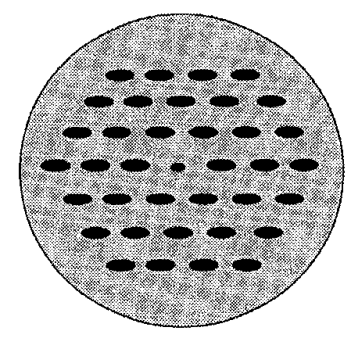

Fig 1. Schematic illustration of fiber crosssections of the structures with a hexagonal lattice of elliptical holes. The core region is formed by a smaller hole in center of the fiber.

The fact of utmost importance for our design is that due to the elliptical shape of holes, which form the cladding of our fiber, the polarization degeneracy of fundamental cladding modes is lifted, and the appearing birefringence may be very large.

In Fig. 2 the modal indices are plotted for fibers with cladding of hexagonal and square lattice of elliptical holes. For comparison we have analyzed the modal indices for core defects formed by a completely missing hole and by a single hole with a smaller size than the cladding holes. It was found that the presence of a smaller hole in the core gives rise to larger birefringence, than in the case of a missing hole.

We have further observed an interesting and unusual feature: the elliptical cladding holes cause a splitting of the fundamental cladding mode into two non-degenerete polarization states. For a region of frequency values the propagation constant for one of the fiber states can be less than one for the 
fundamental cladding polarization states, and can even coincide with it. Naturally, it gives rise to the assumption that this fiber mode is leaky. However, a closer look reveals that it is not true. In Fig. 3 contour maps of the field intensity distributions of fundamental fiber modes are shown for the frequency close to the coincidence point.

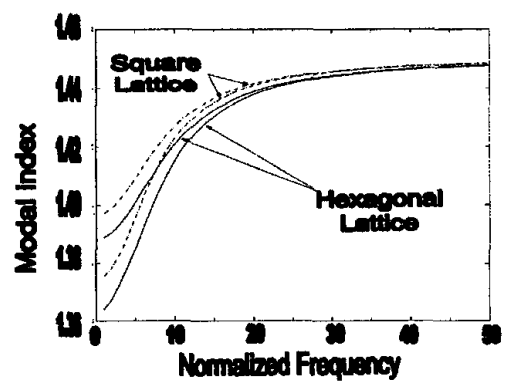

Fig. 2 Modal indices for the fundamental modes of hexagonal (solid lines) and square (dashdotted lines) lattices of elliptical holes with the ratio of largest half-axis to the period of lattice 0.3652 ; and with the axis ratio 0.3 . Refractive index of glass is taken to be 1.45 .

The supposedly leaky mode Fig. 3 (b) appears to be even better localized than the other one. It is possible to give an estimation of how strongly this fiber mode is coupled to the cladding mode [5] at the point of propagation mode coincidence, estimating the beat length $L$. It can be expressed as

$$
L \approx \pi \Lambda / \sqrt{C_{1,2} C_{2,1}}
$$

where

$$
C_{i, j}=\frac{k_{z, j}}{4} \int d x d y\left(\vec{h}_{t, j} \wedge \vec{e}_{t, j}-\vec{h}_{t, j} \wedge \vec{e}_{t, i}\right) \cdot \vec{n}_{z}
$$
and $i, j=1,2$

For the parameters used in Fig. 3 the estimation gives $L$ of about $43.2 \mathrm{~km}$. So the coupling appears to be small indeed. Whereas the estimated beat length between the fundamental modes is approximately $91.1 \mu \mathrm{m}$. Such small beat length indicates that proposed design of the fiber with the

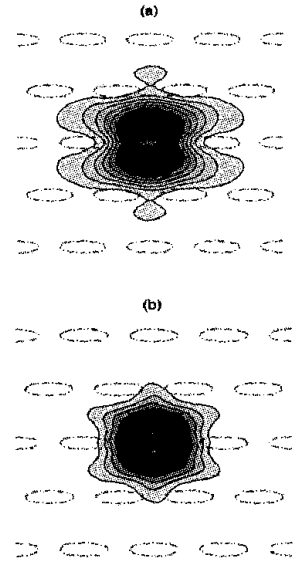

Fig. 3 Contour maps of magnetic field intensity distribution for the first (a) and second (b) fundamental modes of the fiber for the normalized frequency $8.7(\Lambda \mathrm{w} / \mathrm{c})$. Parameters are $A=1 \mathrm{~cm}$ and normalized frequency equal to $8.7(\Lambda w / c)$. The leaky mode is the lower figure (b) - notice, that the field penetrates significantly to the central hole. Dash-dotted contours indicate where the holes are situated.

lattice of elliptical holes for the cladding and smaller elliptical hole for the high-index core defect could be very useful for creating silica-air polarization-preserving fibers, especially if one takes into account the fact of comparatively weak influence of imperfections in positions and shapes of cladding holes.

\section{References:}

1. Knight et al, , Opt. Lett. 21 (1547-9) 1996

2. Knight et al., Science, 285:1537 9, Sept. 1999.

3. Broeng et al., Opt. Fiber Comm. Conf. Paper ThG2-1, 2000.

4. Ferrando el al., Opt. Lett. 24, (276-8), 1999.

5. Snyder and Love, "Optical Waveguide Theory", "Chapman and Hall", London, 1983 , ch. 29,31 . 